fied INSERM's industrial policy. But he accepts that the importance of the industrial venture constituted indirect pressure: "If we had given a negative opinion, we would have been disowning our own institution."

Bihain asserts that it was around this time that he discovered the university was investigating him "without his knowledge", and that he subsequently "telephoned the ministry to seek independent arbitration". In October he filed charges of defamation against Lenfant, although he has now dropped proceedings, understanding the affair to be closed.

On 15 September, Bernard Bigot, then director general of the research ministry, set up a commission of inquiry, chaired by Pierre Corvol of the Collège de France in Paris, which received testimony from more than 20 of the whistleblowers. It submitted its report to the ministry on 28 October.

But the report was never made public, and according to Lenfant the university has itself been unable to obtain a copy, despite a written request to Claude Allègre, the science minister, which he says has gone unanswered.

Jean Rey, an adviser to Allègre, says "we have not excluded [scientific fraud], but we have not established it."

Bihain says he has not seen the Corvol report, but he understands its main conclusions are that additional experiments to verify the identity of the receptor would have been useful. According to Bihain, it also shows that one gel lacked proper molecular weight standards, but he claims that this involved a flawed experiment by a young researcher that was never published.

In written testimony to the Corvol com- mission, Daniel Renou, the INSERM representative in the region until last August, says Bihain treated those who worked for him harshly. "The institute cannot remain deaf to the distress provoked," he wrote.

Renou also submitted evidence of what he claimed were violations of health and safety regulations in the laboratory, and criticized what he describes as Bihain's lack of cooperation on these issues with the authorities. Corvol last week declined to comment on the report, saying only that the affair was "complex".

Controversy also surrounds the fact that the Corvol report was not made available to a meeting of the scientific board of INSERM, at which Bihain's unit was again evaluated, a week after the report was submitted to the ministry. The commission gave a positive decision on the basis of Bihain's presentation, including the fact that a patent had been applied for on his research, and that the results on which this was based had been submitted to a number of scientific journals. But it ruled that the laboratory should be evaluated in two years' time, rather than in four as is usual.

Rose Katz, who chairs the board, says she requested a copy of the Corvol report from Griscelli, but he replied that he did not have one. Katz, who says it would have been "preferable" for the board to have seen the report before ruling on Bihain's laboratory, adds that she has still not been able to see the report. It would have been "more healthy" for this to have been made public, she says.

To complicate matters further, Bigot then carried out his own inquiry, visiting the Rennes laboratory on 28 November and telephoning current and former staff. This second inquiry was needed to "ensure the veracity of the testimonies," says Rey.

Bigot's report, submitted to the ministry on 10 December, cleared the laboratory of misconduct. A summary concludes that "no formal element" refuted the laboratory's research, which, alluding to the industrial interest, Bigot describes as being "on a promising subject that has recently known considerable developments, and which it would be unacceptable to see being abandoned". Nevertheless the report recommends that Bihain "be invited to pay greater attention to his behaviour vis-à-vis his collaborators". (Since 1993, more than 40 staff have left the laboratory or been fired.)

In a letter on 21 January to Daniel Nahon, the new director general of the science ministry, the whistleblowers call for the case to reopened, arguing that the Bigot report fails to take their allegations seriously. The letter - again anonymous, although the signatories' names have been deposited in confidence with Philippe - points out that the Bigot report cites only one paragraph from the Corvol report, stating that "the commission attracts the attention of the minister to the fact that it was convened, by a large number of members and former members of the INSERM unit 391, to consider serious accusations concerning the behaviour of the director of this unit and its scientific activity."

The Philippe report states that some of the laboratory's work poses "many problems". It concludes that "an in-depth analysis carried out by international experts in the field is absolutely necessary."

Declan Butler\& Olivier De Gandt

\title{
New Hubble institute chief seeks broader focus and more work
}

[WASHINGTON] The institute that manages the science programme for the Hubble Space Telescope (HST) should expand its focus beyond that instrument, according to the director chosen to lead the institute into the next century.

Steven Beckwith, who is to take over the helm at the Space Telescope Science Institute (STScI) in Baltimore, Maryland, next September, says one of his main objectives will be bringing in new work to the institute. "HST is the only thing that's done by the institute, and I personally think that's too little for an institute with the kind of resources that are there," says Beckwith, who is at present managing director of the Max Planck Institut für Astronomie in Heidelberg, Germany.

Beckwith, whose appointment was announced by the Association of Universities for Research in Astronomy last week, succeeds Robert Williams as the institute's third director. A native of

Wisconsin, Beckwith was a member of the astronomy faculty at Cornell University before joining Max-Planck, which he helped turn into a leading astronomy centre. He is an expert on star and planet formation, and has been a principal user of Europe's Infrared Space Observatory.

The most obvious new line of work would be to manage the scientific programme for the planned Next Generation Space Telescope (NGST), an infrared-optimized space observatory that

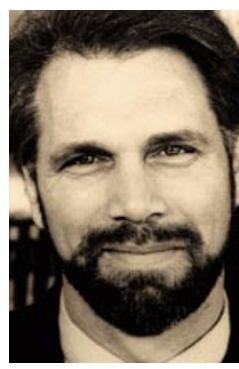

Beckwith: keen for more collaboration. the US National

Aeronautics and Space Administration plans to launch as a successor to Hubble around 2007 (see Nature 389, 651; 1997). The STScI is generally thought to be the leading contender for operating the NGST. But "even that by itself is probably not enough", says Beckwith.

The institute, he says, could be a leader in providing software products, such as those used for data reduction and telescope scheduling, to the general astronomy community. Programs written for the space telescope could be used just as well by other space- and ground-based instruments.

Although some sharing is already going on, he says, the astronomy community has not reached the level of collaboration that he sees among particle physicists. "We don't share as much as we could. It should be possible to save money overall for the field, or at least be able to use the resources we've got to do more than we are, by not duplicating efforts."

This sharing of resources has political problems, he admits, and will happen only if large observatories and astronomy institutions sit down together to "establish a dialogue among the principal actors." Beckwith would like the institute to play a lead role in that dialogue. 